\title{
Examining public acceptance of autonomous mobility
}

\author{
Amin Rezaei and Brian Caulfield \\ Department of Civil, Structural and Environmental Engineering, Trinity College Dublin, \\ Dublin 2, Ireland
}

Please cite as: Rezaei, M., Caulfield, B., Examining public acceptance of autonomous mobility, Travel Behaviour and Society, Vol 21, 2020, pp235-246

\begin{abstract}
Over the last decade, the technology adopted for the automation of transportation has advanced at a pace that now the emergence of Autonomous Vehicles (AV's) might not be as far away as it was thought a few years ago. However, the successful penetration of these vehicles in public roads will mainly rest upon their acceptance and adoption by individual road users and how they embrace this new generation of cars. This paper reports the results of a national survey study conducted among 475 Irish people to evaluate their interest in, and concerns about the adoption of AVs in their daily commute trends. The paper has also analysed people's acceptance and Willingness to Pay (WTP) for AVs compared to Manually Driven Vehicles (MDVs). The results showed that people, in general, were not interested in driving AVs; only one-fifth of the population expressed a high level of interest. Concerns about recording data had an extreme and negative impact on interest since the majority of respondents were not ready to accept AVs' recording of data because of their concerns about privacy. People were also mostly unsure about or not likely to believe in the safety and security of AVs' operation, and they were not at all willing to accept liability for AVs. In addition, the results revealed that cost substantially impacts people's AV purchasing decisions, as when the cost was not an issue, people were much more interested in purchasing an AV.
\end{abstract}

\section{Introduction}

Various studies have assessed users' acceptance and their perceptions regarding the adoption of AVs (Bansal et al., 2016; Kyriakidis et al., 2015; Howard and Dai, 2014; Underwood, 2014; Payre et al., 2014; Schoettle and Sivak, 2014b, 2014c; Casley et al., 2013). Those studies have examined the possible outcomes of adopting AVs by concentrating on safety, costs, and legal liability. They have also provided several insights on the efficiency of AVs and discussed some available technology and research gaps based on individuals' opinions. However, the rapid improvement of smart sensors and other technologies, specifically the application of artificial intelligence in the transportation industry, may have more recently affected users' opinions about the adoption of these vehicles since the users in previous studies were surveyed. To examine this growing area a new assessment of people's perceptions and acceptance of AVs considering the latest improvements in the technology of these vehicles was conducted in this paper.

This paper reports the results of a public survey in Ireland which was conducted to assess the public' interest in and concerns about the application of AVs in their daily commute trends. The findings of this survey also show how much people are willing to pay for an AV and how willing they are to adopt an AV if the cost is not an issue for them. Our paper doesn't give a detailed background to AVs and their development this has been covered in several other studies (Aggelos et al, 2019; Araz, et al, 2019; Marçal et al, 2019). 
The main objective of this research was to analyse road users' perceptions, concerns, and acceptance of automated driving. A lot of research and development is currently ongoing into the production testing and development of AV's, and while this has been growing at great pace the same cannot be said of our understanding of how populations will adapt to these vehicles. The organization of the paper is as follows. Section 2 presents a review of the studies on people's perception and acceptance of AVs. Section 3 presents the data collection method of the survey. Section 4 presents an overview of the socio-demographic characteristics of the survey with a comprehensive analysis of the survey results including response summaries and statistical evaluations. The paper concludes with the main findings of the research in Section 5.

\section{Literature Review}

So far, several safety benefits have been identified as the possible outcomes of adopting AVs. Papadoulis et al. (2019) point out to AV's safer driving than human drivers. Beirigo et al. (2018) highlight AV's capability to deliver freight and unlicensed drivers, and Noy et al. (2018) argue AV's ability in making informed decisions about the upcoming traffic. However, despite the benefits of using AVs, there are still some gaps in the research and the technology for AVs. Such discrepancies should be resolved before the exploitation of AVs on public roads as, otherwise, the gaps in knowledge and technology might affect user acceptance.

Several studies such as Hulse et al. (2018), OECD (2017), Bansal et al. (2016) and some others have reviewed the safety concerns and benefits of adopting AVs. The results of studies in this regard revealed that the first and maybe the most crucial aspect of using an AV in the view of potential users is safety, and it has direct effects on both the transportation network and road users. Also, Chan (2017) indicates safety is often cited as the number one concern relating to AVs and at the same time the main reason for users to adopt AVs.

Fagnant and Kockelman (2015) highlight that intelligent technologies can provide high perception for AVs about their surroundings by utilising image processing tools. Such smart technologies help the vehicle make informed decisions in the case of unexpected incidents, and this represents one of the most substantial advantages of using AVs. However, Rakotonirainy et al. (2014) indicate that the information recorded by such smart sensor technologies might be used against the owner of the vehicle in the case of an accident when the owner is no longer a driver of the car. Besides this, Rakotonirainy et al. (2014) found that AV sensors will have limited coverage, which might lead to incomplete decisions, resulting in an ambiguous understanding of their surrounding objects. However, Katrakazas et al. (2015) say that by using thermal cameras, objects such as pedestrians, cyclists, animals, and vehicles can be identified through the classification of their thermal energy. Such a tool will also work correctly in low light conditions during night trips.

Despite the efforts to assess the probable outcomes of adopting them on public roads, there are still some unanswered questions regarding the privacy and security of AVs. For example, issues related to the types of data which might be stored by AVs, availability of the stored data, the security of AVs against hacking and privacy of AV users (Fagnant and Kockelman, 2015). In this regard, Howard and Dai (2014) showed that individuals are most concerned about losing control of their vehicle due to a security breach to their AVs. Also, the results of a study conducted by Kyriakidis et al. (2015) on 5,000 individuals showed that participants were most concerned about security issues like hacking and misuse of their vehicles by hackers. In this context, Rakotonirainy et al. (2014) indicate that a weak security system in AVs could lead to serious crimes, as human users are the weakest elements in the security chain in an AV network. Stolen data could be misused for unauthorized surveillance of important individuals (Fagnant and Kockelman, 2015). 
According to OECD (2017), the amount of global $\mathrm{CO}_{2}$ emissions from road transport was 6 billion tons in 2015 which, it is estimated, will increase to 7.5 and 10 billion tons of $\mathrm{CO}_{2}$ emissions by 2030 and 2050 respectively. AVs are claimed to be capable of reducing road transport emissions. However, Smith (2013) shows while there might be a decrease in the emissions produced by AVs, the total emissions, from gasoline and dependence on other oil in vehicles might increase. Such an increase in fuel consumption might be as a result of an increase in Vehicle-Mile-Travelled (VMT) by adding new road users such as the elderly and those who were not able to drive before which leads to an increase in traffic congestion (Fagnant and Kockelman, 2015). Such an increase in VMT has been highlighted as an ironic effect of adopting AVs since it is in contradiction with reducing traffic congestion (Smith, 2013). However, Schoettle and Sivak $(2014 b, 2014 c)$ show that AVs will reduce emissions by an average of $65 \%-70 \%$. Also, Fagnant and Kockelman (2015) verify the results of Schoettle and Sivak $(2014 b, 2014 c)$ and add that although the total VMT might increase through the use of AVs, the amount of emissions per mile will reduce. In this context, Bansal et al. (2016) assessed 347 road users' opinions about the environmental impact of AVs in Austin, Texas. Their study showed a positive response about the reduction in emissions and improvements in fuel economy from $88 \%$ and $60 \%$ of participants respectively.

Also, as with all car purchases, AVs need to be affordable for users. After safety, the cost would be considered another essential factor in influencing individuals to think more about the appeal of adopting an AV (Kyriakidis et al., 2015; Schoettle and Sivak, 2014b; Underwood, 2014). In this context, Liu et al. (2019) evaluated WTP for AVs through a public survey of 1,355 participants in China. The results of their study revealed that around $26 \%$ of participants would be unwilling to pay extra for AVs, and approximately $40 \%$ would be willing to spend more than USD 2900. Also, in another study conducted by Howard and Dai (2014), on the public perception of using AVs, with 107 respondents in Berkeley, California, over $65 \%$ of the respondents considered the cost to be a substantial concern regarding the adoption of an AV. One of the most substantial costs of AVs is the equipment and infrastructure. For example, a LIDAR system used in the Google car costs USD 70,000, and the total price of an AV was estimated at around USD 150,000 in 2012 (Howard and Dai, 2014; KPMG, 2012b; Priddle and Woodyard, 2012). Neiger (2016) found that adding autonomous technology to a vehicle could increase the cost of the vehicle to the USD 70,000 - 100,000 price range, based on the price of the LIDAR technology in 2014. However, according to Bosch et al. (2018), the operating cost of AVs will be lower due to lower insurance fees and lower fuel and maintenance costs.

Given the high price of AV technologies, it is essential to understand customers' WTP. In this context, a few studies (Liu et al. (2019), Bansal et al. (2016), Kyriakidis et al. (2015), Schoettle and Sivak (2014b, 2014c), and Casley et al. (2013)) have surveyed individuals' perceptions about the costs and WTP for AVs. In brief, the reviewed studies show that the average WTP to add full self-driving automation is around USD 5,500, which is far below the estimated price of an AV (USD 150,000) in 2012 (Howard and Dai, 2014; KPMG, 2012b; Priddle and Woodyard, 2012) and the price range of USD 70,000 - 100,000 in 2016 (Neiger, 2016). Therefore, this could be a substantial problem in the future adoption of AVs.

The results of the studies by Kyriakidis et al. (2015) and Schoettle and Sivak (2014b) showed that individuals, on average, would be more willing to pay for fully automated vehicles because of amenities such as sleeping, reading, watching movies, talking, playing games, and working. Also, Kyriakidis et al. (2015) found that individuals who spent more time on driving and individuals who used intelligent sensor technologies like Adaptive Cruise Control are more 
willing to adopt AVs. Moreover, Kaur and Several studies have shown that trust of AVs may be one of the key factors in acceptance of AVs (Rampersad, 2018; Xu et al, 2018). Rampersad (2018) studied users' trust of AVs over 101 staff and students of the Flinders University in Australia. The participants in the survey indicated they might be happy to adopt AVs on highways if they could take full control of the AV whenever they wanted to.

In overall, the improvements regarding safety, environment, and other assessed factors related to AVs will not be successful if individuals do not trust these vehicles. The transition towards AVs may not be a straightforward as one may think and many phycological, legal and technical obsticals will need to be overcome (Nikita, et al 2019). Gkartzonikas and Gkritza (2019) provide a comprehensive overview of previous behavioural studies in this field and demonstrate the lack of consensus in the field and point to the research gaps. Becker and Axhausen (2017) highlight a need for more findings on WTP to determine what the adoption curve for AVs may look like in the future. Our paper examines this WTP and aims to provide more evidence in this research gap. In this regard, this paper attempts to add to the literature in this field by presenting a comprehensive study on people's concerns about safety, security, privacy, liability, and their interest and WTP for AVs. This assessment was conducted by running a public survey among 475 Irish road users. The results revealed public concerns about the use of AVs generally. This study also showed how much people are willing to pay for an AV and how willing they are to adopt an AV if the cost is not an issue.

\section{Methods}

\subsection{Data Collection}

The public survey in this study was designed to assess road users' awareness and acceptance of AVs. Before running the main public survey; however, a pilot survey was distributed to make sure the questions of the survey were fair, accurate, descriptive, comprehensive, and understandable to public users. For this purpose, the survey was distributed among some of the students at Trinity College Dublin. The assessment of the pilot survey showed that nearly all (20) participants were satisfied with the survey questions and declared they had no difficulties for reading, understanding, and answering the survey questions. Therefore, the valuation of the pilot survey helped to assure that the main public survey is reliable in the aspect of content and structure. Rezaei (2020) has more detail on the survey, including the full survey text.

The topics examined in the survey came from a comprehensive review of the main topics covered in the literature and some of the comprehensive reviews of the literature conducted to date. This paper examined individuals' perception of, interest in, and concerns about the adoption of AVs in their daily commute trends. The contents of this section explain the overall results about:

- The initial perception of AVs

- Concerns about the safety and security of AVs

- Concerns about the recording of travel data by AVs

- Concerns about and acceptance of AV's legal liability

- Public's decision about purchasing AVs

- WTP for AVs

The survey was distributed via email through a research company in Ireland, and respondents were encouraged to take part in the survey for a chance to win a prize. The responses were checked to be valid for analysis. For this purpose, the respondents who completed the survey to the end and answered more than 34 questions out of 36 were selected for analysis. In total, the research company collected 525 responses to provide a gender balance of $56 \%$ female and 
$44 \%$ male participants. Out of 525 collected responses, 475 were completed and usable for the analysis.

The statistical assessments of the public survey were conducted using the statistical software IBM SPSS Statistics 25. The results of the initial assessments showed that people's awareness and acceptance originates from a diverse range of behaviours. For this, multinomial logit model regression was used to consider a simultaneous impact of different variables and covariates in assessments, which also helps to find the variables with the highest correlation and statistical significance. Also, stepwise logistic regression was adopted for the evaluation of the questions where there was a linear correlation between dependent and independent variables. Furthermore, the cross-tabulation tool of SPSS was adopted in some cases as a supplementary method of assessment to understand the correlation between two different variables.

\subsection{Demographics of the sample}

In total, 475 responses were collected via an online survey. The survey was conducted in January 2019 using an surveying company that randomly distributed it to a National sample. The company sent the survey initially via email to a survey panel of 4,917 panellists, all above the age of 18 and resident in Ireland. A surveying company was used for this study as it could provide access to a diverse sample and could administer prize draws and deal with panellists directly. The sample collected does have fewer under 25 respondents than one might expect. Having considered the age that individuals would purchase a new car this under representation was considered appropriate by the authors. Table 1 demonstrates a summary of the sociodemographic characteristics of the sample of this study compared with those of Census 2016 data (CSO, 2016). The final coloumn of Table 1 shows the percentage difference between the sample collected and that of the 2016 Census (the most recent Census of Ireland). From this data, it can be seen that around $85.1 \%$ of the survey sample possessed a driving license which is $25.9 \%$ greater than the number of licensed drivers in 2016 (according to 2016 Census data). In this context, and looking at the number of cars in Table 1, the percentage of people who had one car in the survey was $15.1 \%$ higher than that of 2016 Census data. Therefore, such an increase in the percentage of licensed drivers and ownership of one car could be an indication of the improvement in mobility services and facilitation in this context. Although the overall car ownership did not change from 2016, there has been a change in the distribution of cars where more people owned at least one car compared to 2016.

It could also be observed from Table 1 that a greater percentage of the participants were aged between 36-50 years old (compared to 2016 Census data), where the participants' distribution in other age ranges was close to the recorded data of 2016 Census. Furthermore, Table 1 shows a $5.0 \%$ difference between the percentages of Male in the sample $(44.4 \%)$ and Census data (49.4\%). However, it is mindful to consider that this survey was conducted online, and those male participants aged 26-35 and 36-50 years old who might have been busy at work during the day were not covered in the survey. 
Table 1. Characteristics of the survey sample compared with the 2016 Census (CSO, 2016)

\begin{tabular}{|c|c|c|c|c|c|}
\hline \multirow[t]{2}{*}{ Variable } & \multicolumn{2}{|c|}{$\begin{array}{l}\text { Survey } \\
\text { Sample }\end{array}$} & \multicolumn{2}{|c|}{ Census (2016) } & \multirow{2}{*}{$\begin{array}{l}\text { Difference between } \\
\text { the survey sample } \\
\text { and the } 2016 \text { Census } \\
\%\end{array}$} \\
\hline & $\mathbf{N}$ & $\%$ & $\mathbf{N}$ & $\%$ & \\
\hline \multicolumn{6}{|l|}{ Driving License } \\
\hline Yes & 400 & 85.1 & $2,820,528$ & 59.2 & 25.9 \\
\hline No & 70 & 14.9 & $1,941,337$ & 40.8 & 25.9 \\
\hline Total & $470 *$ & 100.0 & $4,761,865$ & 100.0 & 0.0 \\
\hline \multicolumn{6}{|l|}{ Car Ownership } \\
\hline Yes & 382 & 80.9 & $3,899,967$ & 81.9 & 1.0 \\
\hline No & 90 & 19.1 & 861,898 & 18.1 & 1.0 \\
\hline Total & $472 *$ & 100.0 & $4,761,865$ & 100.0 & 0.0 \\
\hline \multicolumn{6}{|l|}{ Number of Cars } \\
\hline 0 & 90 & 18.9 & 737,094 & 18.9 & 0.0 \\
\hline 1 & 284 & 59.8 & $1,743,285$ & 44.7 & 15.1 \\
\hline 2 & 88 & 18.5 & $1,212,890$ & 31.1 & 15.3 \\
\hline 3 or more & 13 & 2.1 & 183,298 & 4.7 & 2.6 \\
\hline Total & 475 & 100.0 & $3,899,967$ & 100.0 & 0.0 \\
\hline \multicolumn{6}{|l|}{ Age of car } \\
\hline $\begin{array}{l}\text { No car } \\
\text { ownership }\end{array}$ & 90 & 19.1 & $*$ & $*$ & 19.1 \\
\hline $0-2$ years old & 49 & 10.4 & $*$ & $*$ & 10.4 \\
\hline $2-5$ years old & 84 & 17.8 & $*$ & $*$ & 17.8 \\
\hline $5-7$ years old & 52 & 11.0 & $*$ & $*$ & 11.0 \\
\hline $7-10$ years old & 89 & 18.9 & $*$ & $*$ & 18.9 \\
\hline $\begin{array}{l}\text { Above } 10 \text { years } \\
\text { old }\end{array}$ & 108 & 22.9 & $*$ & $*$ & 22.9 \\
\hline Total & $472 *$ & 100.0 & $*$ & $*$ & 100.0 \\
\hline \multicolumn{6}{|c|}{ Age (of participant) } \\
\hline $0-18$ years old & $* *$ & $* *$ & $1,128,514$ & 23.7 & 23.7 \\
\hline $18-25$ years old & 9 & 1.9 & 449,780 & 9.4 & 7.5 \\
\hline $26-35$ years old & 87 & 18.4 & 683,677 & 14.4 & 4.0 \\
\hline $36-50$ years old & 207 & 43.8 & $1,053,434$ & 22.1 & 21.7 \\
\hline $50+$ years old & 170 & 35.9 & $1,446,460$ & 30.4 & 5.5 \\
\hline Total & $473 *$ & 100.0 & $4,761,865$ & 100.0 & 0.0 \\
\hline \multicolumn{6}{|l|}{ Gender } \\
\hline Male & 210 & 44.4 & $2,354,428$ & 49.4 & 5.0 \\
\hline Female & 262 & 55.4 & $2,407,437$ & 50.6 & 4.8 \\
\hline Other & 1 & 0.2 & $* *$ & $* *$ & 0.2 \\
\hline Total & $473 *$ & 100.0 & $4,761,865$ & 100.0 & 0.0 \\
\hline
\end{tabular}

In general, the number of cars, the overall rate of car ownership, and other statistics of the sample were found to be representative of the population of Ireland compared to 2016 Census 
data. Therefore, this verifies the authenticity of the sample recorded for the survey of the current study. Each of these six areas of concern listed below are analyzed against socio economic variables in the paper. One of the variables that was omitted and would be very valuable to future studies would be to measure how much people currently use their car. The thinking behind this is that those with greater mobility needs may be more likely to derive greater benefits from AVs.

\subsection{Analysis Approach}

The research examines individual's awareness and acceptance originate from a diverse range of behaviours, and therefore, a simultaneous impact of various variables and covariates should be considered in assessments. Therefore, Multinomial Logit regression method was used for the assessments in this regard that could be extended to models with multiple explanatory variables (El-Habil, 2012). In this context, the study evaluated different variables which could be closely related to the dependent variables to find those variables with the highest correlation and statistical significance. For the Multinomial Logit model to be used, there are a few assumptions which must be passed. One is that the dependent variables should be nominal (Laerd, 2019). In the case of this study, despite that the dependent variables were (qualitatively) ordinal, they were converted to nominal values first, so an Multinomial Logit model could be adopted. Another assumption of the Multinomial Logit model is that one or more independent variables should be continuous, nominal, or ordinal (Laerd, 2019). However, ordinal variables should be treated as nominal, which is done in this research - ordinal independent variables were transformed to nominal variables and adopted in the Multinomial Logit model. Moreover, the assessments revealed that the Multinomial Logit model responded well with valid test results for model fit tests. Therefore, changing the evaluation method did not seem necessary. However, the authors recoganise other approaches such as ordinal regression analysis could have been used.

\section{Results}

\subsection{Initial perception of AVs and Concerns about Safety and Security of AVs}

Error! Reference source not found. demonstrates the initial perception and interest of participants about AVs. The evaluation in this sub-section shows how informed the participants were about AVs and how interested they were in such a vehicle. The results showed that less than half of the total participants, in general, had not heard about AVs, and almost a third had "somewhat" heard about it.

This sub-section explains participants' perception of the safety and security of AVs. In this context, questions were asked about AVs' safety and security compared with vehicles with human drivers, AV's safety and security with or without a steering wheel, AVs' quick driving reactions compared with human drivers and some others. The results from the survey questions in this sub-section would provide an understanding of how much such concerns might affect people's decision regarding the adoption of AVs. The overall results of the evaluations in this regard are presented in Table 2. Participants, in general, believed that AVs would be 'somewhat' safer and more secure than human drivers, which in some way conveys a neutral opinion in this regard. The results also revealed more concern when participants were asked how safe and secure they would feel if AVs had no steering wheel. In this vein, participants declared they would feel safer and more secure in an AV with steering wheel and a manual override control system than an AV without such types of equipment. Table 2 demonstrates that participants indicated they would feel 'somewhat concerned' about AV's quick reaction in 
unexpected driving incidents. Also, the participants of the study were asked how much they would be interested in adopting AVs if AVs could only operate in some limited areas in the city and not everywhere around the country. In Table 2 the researchers used a 3-point likert scale, it could be argued that a 5 or 7 point scale would have been better and this might be a potential limitation of the research.

Table 2. The Overall Concerns about Safety and Security and knowledge of AVs

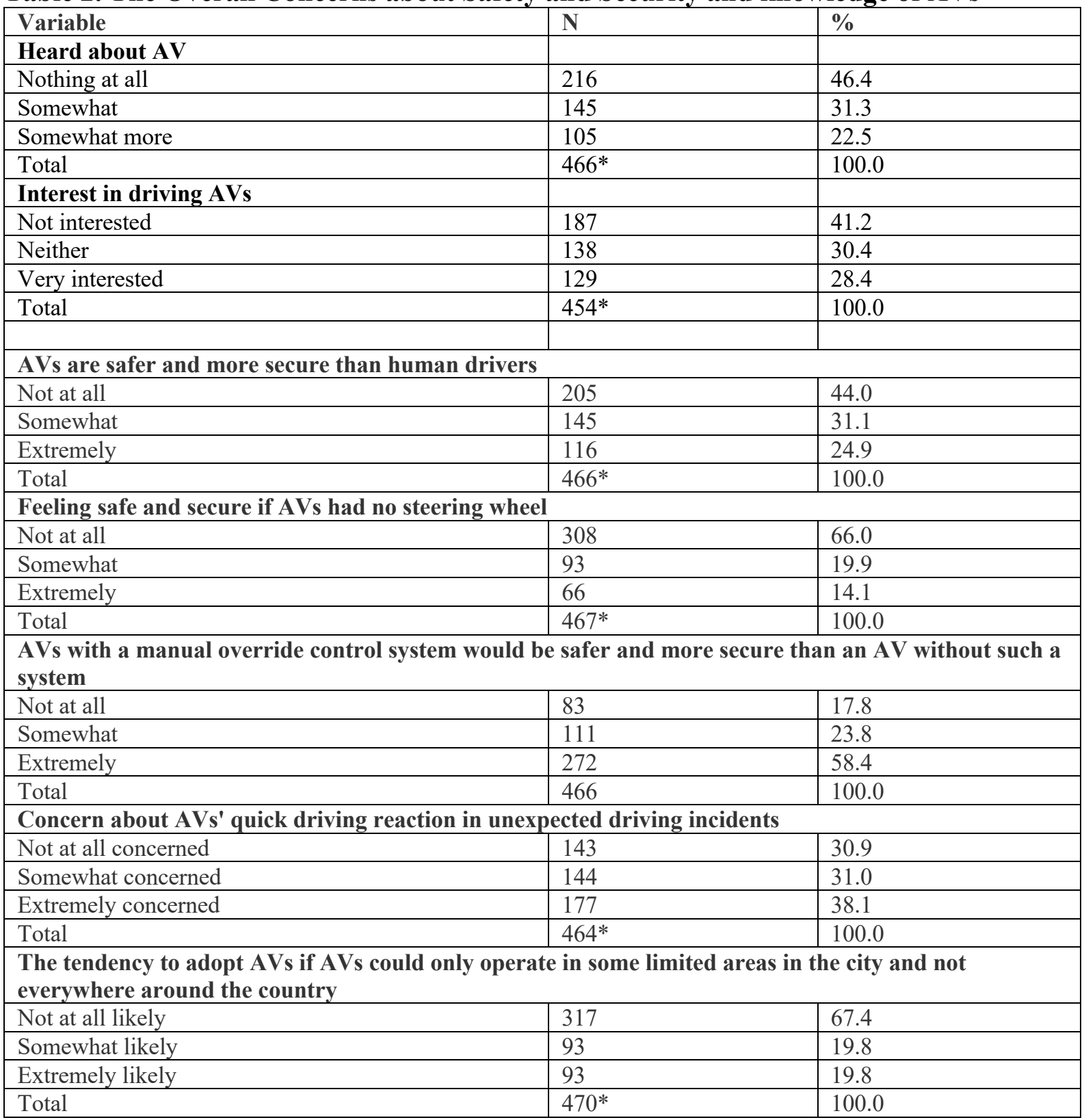

* Respondants did not answer all questions

The results of the multinomial logit model are presented in Table 3. The model fitting tests presented $p$ values below 0.05 , meaning that the model results are statistically significant in 
general. The correlation between the model's predicted values and the actual values is also validated by 0.517 pseudo R-squared value in the Nagelkerke test. The likelihood ratio test revealed that 'number of cars' and two of the model covariates are statically significant, as the $p$ values are less than 0.05 . However, 'gender', 'age', and the other model covariates do not provide appropriate correlation with some other data. Such a discrepancy in likelihood ratio tests requires further investigation.

Results of the multinomial logit model show that feeling safe and secure about AVs' quick reaction attained statistical significance for the answer options 'somewhat' and 'extremely'; the positive B-coefficients and $p$ values below 0.05 are the proof of model significance. In this model the age and number of cars variables have been merged due to the low number of respondents in some of these variables. Also, the higher odds ratio for 'extremely' indicates that feeling safe and secure about AVs' reaction had affected people's perceptions of AVs as being remarkably safer and more secure than human drivers. The negative B-coefficients for females show that they are less likely than males to be neutral or extremely positive about the statement that AVs are safer and more secure than human drivers. The age group results reveal that people from 36-50 years old are more likely to be neutral and extremely positive about AVs safe and secure operation compared to humans. Also, respondents with one car had the highest B-coefficient and odds ratio, meaning these people were more likely to believe that AVs are safer than humans.

Overall, the assessment in this Section finds that only a few percent of respondents believe in AVs' safe and secure operation when AVs are compared to human drivers. Also, the number of cars respondents own had an impact on their positive opinion such that people with five cars and above were more likely to believe in AVs' extreme capabilities, while people with one car were more neutral in this matter. Also, males, in general, were more likely than females to think that AVs will be safer and more secure than human drivers.

Table 3. Results of the multinomial logit model model for AVs' safe and secure operation compared to human drivers

\begin{tabular}{|c|c|c|c|}
\hline Variable & $\begin{array}{l}\text { Model } \\
\text { Coefficient: (B) }\end{array}$ & $\begin{array}{l}\text { Odds Ratio: } \\
\text { Exp (B) }\end{array}$ & Sig. \\
\hline \multicolumn{4}{|c|}{ AVs are safer and more secure than human drivers ${ }^{a}$ : Somewhat } \\
\hline 'Not at all' feeling safe and secure about AVs' quick reaction & -.530 & .588 & .115 \\
\hline 'Somewhat' feeling safe and secure about AVs' quick reaction & 1.586 & 4.884 & .000 \\
\hline 'Extremely' feeling safe and secure about AVs' quick reaction & $0^{\mathrm{b}}$ & & \\
\hline Gender (Female) & -.491 & .612 & .081 \\
\hline Gender (Male) & $0^{\mathrm{b}}$ & & \\
\hline Age $(18-35)$ & .021 & 1.021 & .067 \\
\hline Age $(36-50)$ & .036 & 1.037 & .022 \\
\hline Age $(50+)$ & $0^{\mathrm{b}}$ & & \\
\hline Number of cars (1) & .084 & 1.088 & 0.001 \\
\hline Number of cars (More than one) & $0^{\mathrm{b}}$ & & \\
\hline \multicolumn{4}{|l|}{ AVs are safer and more secure than human drivers ${ }^{\text {a }}$ : Extremely } \\
\hline 'Not at all' feeling safe and secure about AVs' quick reaction & -1.536 & .215 & .000 \\
\hline 'Somewhat' feeling safe and secure about AVs' quick reaction & .409 & 1.505 & .228 \\
\hline 'Extremely' feeling safe and secure about AVs' quick reaction & $0^{\mathrm{b}}$ & & \\
\hline Gender (Female) & -.951 & .387 & .001 \\
\hline Gender (Male) & $0^{\mathrm{b}}$ & & \\
\hline Age $(18-35)$ & .638 & 1.894 & .109 \\
\hline Age $(36-50)$ & .385 & 1.470 & .227 \\
\hline Age $(50+)$ & $0^{\mathrm{b}}$ & & \\
\hline Number of cars (1) & -.310 & .733 & .323 \\
\hline Number of cars (More than one) & $0^{\mathrm{b}}$ & & \\
\hline
\end{tabular}


a. The reference category is: Not at all

b. This parameter is set to zero because it is redundant

It is worth noting that an AV with level 5 autonomy (SAE, 2016) will conduct all driving operations by itself; a steering wheel might or might not be in the vehicle. However, it is crucial to understand how safe and secure the respondents would feel if their car had no steering wheel. Therefore, further investigation was conducted on the impact of the advantages of adopting AVs on how safe and secure would AVs be without a steering wheel. In this regard, the parameter "feeling safe and secure in an AV without a steering wheel" is considered as the dependent variable of the multinomial logit model in this step of the investigation. Hence, the question in this step evaluates such a perception, adopting three independent variables: 'AVs are safer and more secure than human drivers', 'feeling safe and secure about AVs quick reaction in accidents', and 'interested in driving AV'. Also, two covariates have been acquired, which help to correlate the answers with some other user perceptions about AVs. The covariates were 'agree that AVs should record data', and 'purchase AV when it is fully developed and tested'. Table 4 shows the answer summary for this assessment. Results show that $66 \%$ of the users (427 observations), in general, would not feel safe and secure in an AV without a steering wheel, while $20.8 \%$ were somewhat likely to have a positive view about it. Only $13.2 \%$ declared an extremely positive attitude about a fully driverless AV.

Table 4. Case processing summary of how safe and secure would AVs be without a steering wheel

\begin{tabular}{|c|c|c|c|}
\hline \multicolumn{2}{|l|}{ Variable } & $\mathbf{N}$ & $\%$ \\
\hline \multirow{4}{*}{$\begin{array}{l}\text { Feeling safe and secure in an AV } \\
\text { without a steering wheel }\end{array}$} & $1=$ Not at all likely & 282 & 66.0 \\
\hline & $2=$ Somewhat likely & 89 & 20.8 \\
\hline & $3=$ Extremely likely & 56 & 13.2 \\
\hline & Total & 427 & 100 \\
\hline \multirow{4}{*}{$\begin{array}{l}\text { AVs are safer and more secure than } \\
\text { human drivers }\end{array}$} & $1=$ Not at all likely & 186 & 43.6 \\
\hline & $2=$ Somewhat likely & 135 & 31.6 \\
\hline & $3=$ Extremely likely & 106 & 24.8 \\
\hline & Total & 427 & 100 \\
\hline \multirow{4}{*}{$\begin{array}{l}\text { Feeling safe and secure about AVs } \\
\text { quick reaction in accidents }\end{array}$} & $1=$ Not at all concerned & 129 & 30.2 \\
\hline & $2=$ Somewhat concerned & 134 & 31.4 \\
\hline & $3=$ Extremely concerned & 164 & 38.4 \\
\hline & Total & 427 & 100 \\
\hline \multirow[t]{4}{*}{ Interested in driving $\mathrm{AV}$} & $1=$ Not interested & 177 & 41.5 \\
\hline & $2=$ Neither & 128 & 30.0 \\
\hline & $3=$ Very interested & 122 & 28.5 \\
\hline & Total & 427 & 100 \\
\hline
\end{tabular}

Moreover, Table 5 shows the results of the multinomial logit model and model fitting information of this evaluation. The model fitting test of this assessment presented $p$ values below 0.05 , which indicates the results are statistically significant. Also, the likelihood ratio tests verify the significance of the correlation between answers by providing $p$ values below 0.05 for all except one independent variable. However, the model in general looks valid, and the correlation between the model's predicted values and the actual values is also validated by the Nagelkerke R-squared value of $51.9 \%$.

Viewing the B-coefficients and odds ratios in Table 9 with regard to the reference category, the analysis evaluates the results from respondents who said they would feel extremely safe and secure in driverless AVs. According to Table 9, respondents who believed in the safe operation 
of driverless AVs were $90 \%(\operatorname{Exp}(B)=1.9)$ more likely to agree that AVs should record data. Also, those who believed in the safe operation of driverless AVs were $43 \%(\operatorname{Exp}(B)=1.43)$ more likely to have an interest in purchasing AVs when they are fully developed than the people who would feel 'not at all' safe and secure in driverless AVs. Also, the results make clear that those who were not interested in driverless AVs believed AVs are 'not at all' safer and more secure than human drivers, and they did not feel safe and secure about AVs' quick reaction in accidents. The small values for the odds ratios for these independent variables are proof of such a declaration. For example, people who were extremely interested in driverless AVs were $97.7 \%$ less likely $(1-0.023)$ to feel that AVs were 'not at all' safer and more secure than human drivers than the reference category. Therefore, in general, the assessment verifies that $66 \%$ of respondents lack interest in AVs without steering wheels. The reasons for such lack of interest could be concerns about recording data, not feeling safer and more secure in AVs than with human drivers, and concerns about AVs' quick reaction in accidents.

Table 5. Results of the multinomial logit model for how safe and secure would AVs be without a steering wheel

\begin{tabular}{|c|c|c|c|}
\hline Variable & $\begin{array}{l}\text { Model } \\
\text { Coefficient: (B) }\end{array}$ & $\begin{array}{l}\text { Odds Ratio: } \\
\text { Exp (B) }\end{array}$ & Sig. \\
\hline \multicolumn{4}{|c|}{ Feeling safe and secure in an AV without a steering wheela: somewhat likely } \\
\hline Agree that AVs should record data & 0.271 & 1.311 & 0.033 \\
\hline Purchase AV when It is fully developed and tested & 0.267 & 1.306 & 0.018 \\
\hline 'Not at all' feeling that AVs are safer and more secure than humans & -2.385 & 0.092 & 0.000 \\
\hline 'Somewhat' feeling that AVs are safer and more secure than humans & -0.833 & 0.435 & 0.022 \\
\hline 'Extremely' feeling that AVs are safer and more secure than humans & $0^{\mathrm{b}}$ & & \\
\hline 'Not at all concerned' about AVs' quick reaction in accidents & -0.526 & 0.591 & 0.216 \\
\hline 'Somewhat concerned' about AVs' quick reaction in accidents & 0.865 & 2.375 & 0.009 \\
\hline 'Extremely concerned' about AVs' quick reaction in accidents & $0^{\mathrm{b}}$ & & \\
\hline 'Not at all concerned' interested in driving AVs & 0.620 & 1.859 & 0.185 \\
\hline 'Neither' interested in driving AVs & 0.458 & 1.581 & 0.248 \\
\hline 'Very interested' interested in driving AVs & $0^{\mathrm{b}}$ & & \\
\hline \multicolumn{4}{|c|}{ Feeling safe and secure in an $\mathrm{AV}$ without a steering whee ${ }^{\mathbf{a}}$ : Extremely likely } \\
\hline Agree that AVs should record data & 0.642 & 1.900 & 0.000 \\
\hline Purchase AV when It is fully developed and tested & 0.363 & 1.438 & 0.019 \\
\hline 'Not at all' feeling that AVs are safer and more secure than humans & -3.788 & 0.023 & 0.000 \\
\hline 'Somewhat' feeling that AVs are safer and more secure than humans & -2.397 & 0.091 & 0.000 \\
\hline 'Extremely' feeling that AVs are safer and more secure than humans & $0^{\mathrm{b}}$ & & \\
\hline 'Not at all concerned' about AVs' quick reaction in accidents & -0.579 & 0.560 & 0.270 \\
\hline 'Somewhat concerned' about AVs' quick reaction in accidents & -0.385 & 0.680 & 0.402 \\
\hline 'Extremely concerned' about AVs' quick reaction in accidents & $0^{\mathrm{b}}$ & & \\
\hline 'Not at all concerned' interested in driving AVs & -0.718 & 0.488 & 0.367 \\
\hline 'Neither' interested in driving AVs & 0.358 & 1.431 & 0.487 \\
\hline 'Very interested' interested in driving AVs & $0^{\mathrm{b}}$ & & \\
\hline \multicolumn{4}{|c|}{$\begin{array}{l}\text { Chi-Square: } 237.820 \text {, Degrees of freedom: } 16 \text {, P-value: } 0.000 \text {, Pseudo R-square: } 0.519,-2 \text { Log Likelihood, } \\
314.539\end{array}$} \\
\hline
\end{tabular}

\subsection{Recording Travel Data by AVs}

This sub-section presents the respondents' previous knowledge about and concerns regarding the record of data by AVs. The results from this sub-ection would help to understand how much the record of data by AVs might impact upon user's acceptance of the adoption of AVs. As shown in Table 6, the majority of the participants (67.4\%) did not know that AVs might record 
travel data, while $32.6 \%$ declared they were aware of such an issue. In this context, the evaluation regarding the concern about the privacy of AVs' travel data shows that participants, in general, were 'somewhat concerned' about the privacy of their travel data recorded by AVs. However, people were neutral (undecided) whether AVs should record travel data or not.

In addition to the assessment regarding privacy concerns and the recording of data by AVs, participants were asked with whom they would prefer to share the recorded data if recording data was one of the mandatory rules and conditions for adopting AVs. According to the summary of responses in Table 6, local or national transport authorities and insurance companies are the two most trusted agencies that people would prefer to share their AV data with. After these, car manufacturers and traffic consultancies are in the next level of preferences. Also, around $8.2 \%$ of the participants submitted other answers, among which some participants believing no one should have access to the data recorded by AVs, and in case of mandatory access, the data should be accessible only by the owners. Some also said they might prefer to share it with police only in the case of an accident.

Table 6. Knowledge and concerns regarding the record of travel data by AVs

\begin{tabular}{|l|l|l|}
\hline Variable & N & $\%$ \\
\hline Previous knowledge that AVs might record travel data & 154 & 32.6 \\
\hline Yes & 319 & 67.4 \\
\hline No & 473 & 100.0 \\
\hline Total & \multicolumn{2}{l|}{} \\
\hline Concern about the privacy of AVs' travel data & 27.6 \\
\hline Not at all concerned & 131 & 25.9 \\
\hline Somewhat concerned & 123 & 46.5 \\
\hline Extremely concerned & 221 & 100.0 \\
\hline Total & 475 & \\
\hline Agree/disagreements about AVs to record travel data & \multicolumn{2}{|l|}{} \\
\hline Disagree & 153 & 32.9 \\
\hline Undecided & 174 & 37.4 \\
\hline Agree & 138 & 29.7 \\
\hline Total & 465 & 100.0 \\
\hline Who should access to AVs' travel data (MRA) & \multicolumn{2}{|l|}{} \\
\hline Local/national transport authorities & 175 & 43.8 \\
\hline Insurance companies & 207 & 41.4 \\
\hline Car manufacturers & 88 & 37.0 \\
\hline Local/national transport consultant companies & 196 & 18.6 \\
\hline Other & 39 & 8.3 \\
\hline
\end{tabular}

For further evaluation in this regard, a cross-tabulation has been conducted to evaluate the correlation of concerns about the privacy of data and recording data by AVs (shown in Table 7). In total, 465 observations were recorded for this assessment, with $218(46.9 \%)$ of the respondents expressing an utmost concern about the privacy of the recorded data in AVs. Out of 218 concerned respondents, $45.9 \%$ disagreed that AVs should record data, and $30.3 \%$ of them were neutral on the subject; only $23.9 \%$ of the respondents agreed that AVs should record data. The assessment within the 'recording of data' confirms a correlation between 'concerns about the privacy of data' and 'recording data' by representing $65.4 \%$ disagreement about the 'recording of data'.

Also, of the 129 respondents who were not at all concerned about the privacy of data, $39.5 \%$ agreed that AVs should record data, and $36.4 \%$ were neutral about it. The comparison of the 
expected values and the observed results in the survey is also verified by the Chi-square $\left(\chi^{2}\right)$ value of 37.66 and the Pearson $p$ value of less than 0.05 .

In general, the assessment finds that $32.9 \%$ of all participants disagreed with the recording of data by AVs, and $37.4 \%$ were neutral; only $29.7 \%$ agreed that AVs should record data. Therefore, the assessment implies that the recording of data by AVs is not acceptable to the majority of respondents because it raises concerns about data privacy. Such concerns could affect users' interest in and acceptance of AVs on public roads.

Table 7. Cross-tabulation of the privacy of recorded data in AV versus acceptance of recording of data by AV

\begin{tabular}{|c|c|c|c|c|c|c|}
\hline \multirow{2}{*}{\multicolumn{3}{|c|}{ Variable }} & \multicolumn{3}{|c|}{$\begin{array}{l}\text { Agree that AVs should record } \\
\text { data }\end{array}$} & \multirow[t]{2}{*}{ Total } \\
\hline & & & Disagree & Undecided & Agree & \\
\hline \multirow{9}{*}{$\begin{array}{l}\text { Concerned } \\
\text { about the } \\
\text { privacy of } \\
\text { recorded } \\
\text { data in AV }\end{array}$} & \multirow{3}{*}{$\begin{array}{l}\text { Not at all } \\
\text { concerned }\end{array}$} & Count & 31 & 47 & 51 & 129 \\
\hline & & $\%$ within privacy & 24.0 & 36.4 & 39.5 & 100.0 \\
\hline & & $\%$ within record data & 20.3 & 27.0 & 37.0 & 27.7 \\
\hline & \multirow{3}{*}{$\begin{array}{l}\text { Somewhat } \\
\text { concerned }\end{array}$} & Count & 22 & 61 & 35 & 118 \\
\hline & & $\%$ within privacy & 18.6 & 51.7 & 29.7 & 100.0 \\
\hline & & $\%$ within record data & 14.4 & 35.1 & 25.4 & 25.4 \\
\hline & \multirow{3}{*}{$\begin{array}{l}\text { Extremely } \\
\text { concerned }\end{array}$} & Count & 100 & 66 & 52 & 218 \\
\hline & & $\%$ within privacy & 45.9 & 30.3 & 23.9 & 100.0 \\
\hline & & $\%$ within record data & 65.4 & 37.9 & 37.7 & 46.9 \\
\hline \multirow{3}{*}{\multicolumn{2}{|c|}{ Total }} & Count & 153 & 174 & 138 & 465 \\
\hline & & $\%$ within privacy & 32.9 & 37.4 & 29.7 & 100.0 \\
\hline & & $\%$ within record data & 100.0 & 100.0 & 100.0 & 100.0 \\
\hline
\end{tabular}

\subsection{AV's Legal Liability}

Table 8 presents the overall results of the evaluations regarding participants' willingness to accept AVs' legal liability and the authorised agent or groups who should accept such responsibility. The results from this sub-section would impact upon user's acceptance of AVs. The results represented that $57.2 \%$ of the total participants, were not willing to accept AVs' liability, and $28.9 \%$ had a neutral perception in this regard; only $13.9 \%$ showed a high willingness for accepting AVs' legal liability.

Additionally, participants were asked who should accept the highest responsibility for the AV in case of an accident, where the selection of multiple responses was allowed (MRA); Table 13 shows people's responses to this question. Among the survey responses, the AV manufacturer was selected by $70.7 \%$ of the people as the entity that should accept the highest level of liability for the AVs in case of accidents. By much lower percentage, insurance companies and AV owners were selected as the next most responsible groups, by $22.2 \%$ and $19.0 \%$ of respondents, respectively. Smaller numbers of participants submitted other responses that indicated they believed the assignment of responsibility for AVs depends on the circumstances and the nature of the incident. Note these three percentages total to well over $100 \%$ because respondents select multiple answers.

Table 8. The overall responses regarding the acceptance of the AVs' legal liability in accidents

\begin{tabular}{|l|l|l|}
\hline Variable & N & \% \\
\hline Willing to accept AV's legal liability in accidents & 271 & 57.2 \\
\hline Nothing at all & 137 & 28.9 \\
\hline Somewhat & 66 & 13.9 \\
\hline Some what more & 474 & 100.0 \\
\hline Total & \\
\hline
\end{tabular}




\begin{tabular}{|l|l|l|}
\hline The group or agency which should accept the highest legal liability of AVs in accidents \\
\hline AV manufacturers & 66 & 70.7 \\
\hline Insurance companies & 335 & 22.2 \\
\hline AV owners & 90 & 19.0 \\
\hline National Transport Authorities & 59 & 13.9 \\
\hline Local traffic control centres & 105 & 12.5 \\
\hline Other & 14 & 3.0 \\
\hline
\end{tabular}

The study then investigated the impact of AVs' safe and secure operation compared to human drivers and the impact of such perception on respondents' willingness to accept AVs' liability. Looking at the results from Table 9,43.9\% of the total (465) participants in this investigation believed that AVs are not at all safer and more secure than human drivers. Within those $43.9 \%$ respondents, $65.7 \%$ declared they do not want to accept AVs' liability under any conditions. The responses to the question about liability confirm the correlation by showing that $50.4 \%$ of people who are not willing to accept AVs' liability, do not believe that AVs might be safer and more secure than human drivers. Also, $31.2 \%$ of the total participants in this investigation were neutral as to whether AVs would be safer and more secure than human drivers. The other group in this investigation were those who believed AVs would be 'Extremely' safer and more secure than human drivers, which was the view of $24.9 \%$ of the total participants. However, $46.6 \%$ of this last group did not want to accept AVs' liability despite their belief in AVs' safe and secure operation. However, the results within liability show that the majority of the people in this group who are extremely or somewhat willing to accept AV's liability do believe that AVs are extremely safer and more secure than human drivers. Therefore, results overall suggest that the majority of participants are not willing to accept AVs' liability, not even those who believe in AVs' safe and secure operation, but those who are willing to accept liability have more trust in AVs' safe and secure operation.

The study then evaluated how much feeling safe and secure about AVs' quick reaction in accidents could be related to willingness to accept liability. Table 10 also shows the crosstabulation of this assessment. Results from Table 9 show that $38.2 \%$ of all participants in this assessment were extremely concerned about AVs' quick reaction in accidents, of which $53.1 \%$ were not at all willing to accept liability, and $24.9 \%$ were neutral about liability. Only $22 \%$ of those $38.2 \%$ were willing to accept AVs' liability, and they had an extreme concern about AVs' quick reaction in accidents. The rest of the participants in the survey were evenly split between those who were somewhat concerned and those who were not at all concerned about AVs' quick reaction. Around $55.9 \%$ of the somewhat concerned people did not want to accept liability at all, while $65 \%$ of the people who were not at all concerned about AVs' quick reaction in accidents declared they also were not willing to accept liability. In general, $57.7 \%$ of all respondents were not willing to accept liability under any condition, $28.5 \%$ were somewhat willing, and only $13.8 \%$ showed a high willingness to accept AVs' liability. Therefore, the study finds that few people are willing to accept AVs' liability because of the concern about AVs' quick reaction.

As was seen in the literature review, legal liability has been considered as one of the barriers to adopting AVs in several survey studies. Therefore, the study in this sub-section assesses potential interest and some other features that might affect users' willingness to accept AVs' liability.

First, the study asked about people's interest in driving AVs and correlated the results with the responses regarding liability acceptance for AVs. Out of 453 observations in this assessment, 187 participants $(41.3 \%)$ were 'not interested' in driving AVs. Within those 187 respondents, $64.7 \%$ of them rated 'nothing at all' for liability acceptance. Among the 137 participants $(30 \%)$ who had a neutral level of interest in driving AVs, $54.7 \%$ did not want to accept liability at all. 
The last group were those who showed a high interest in driving AVs, with 129 responses representing $28 \%$ of all participants. Out of 129 interested respondents, $48.1 \%$ declared they did not want to accept liability at all, and $31 \%$ were neutral about accepting liability. Only $20.9 \%$ showed a greater deal of willingness to accept liability. Table 9 shows the crosstabulation of interest in driving AV and respondents' willingness to accept liability for AVs. The analysis shows that people, in general, are not willing to accept AVs' liability, even the majority of those who are interested in driving an AV. The accuracy of the analysis and the statistical significance are confirmed with a Pearson $p$ value of $0.017(<0.05)$.

Table 9. Cross-tabulation of AVs' safe and secure operation, safe and secure about AVs' quick reaction and Interested in driving AV versus willingness to accept AV's liability

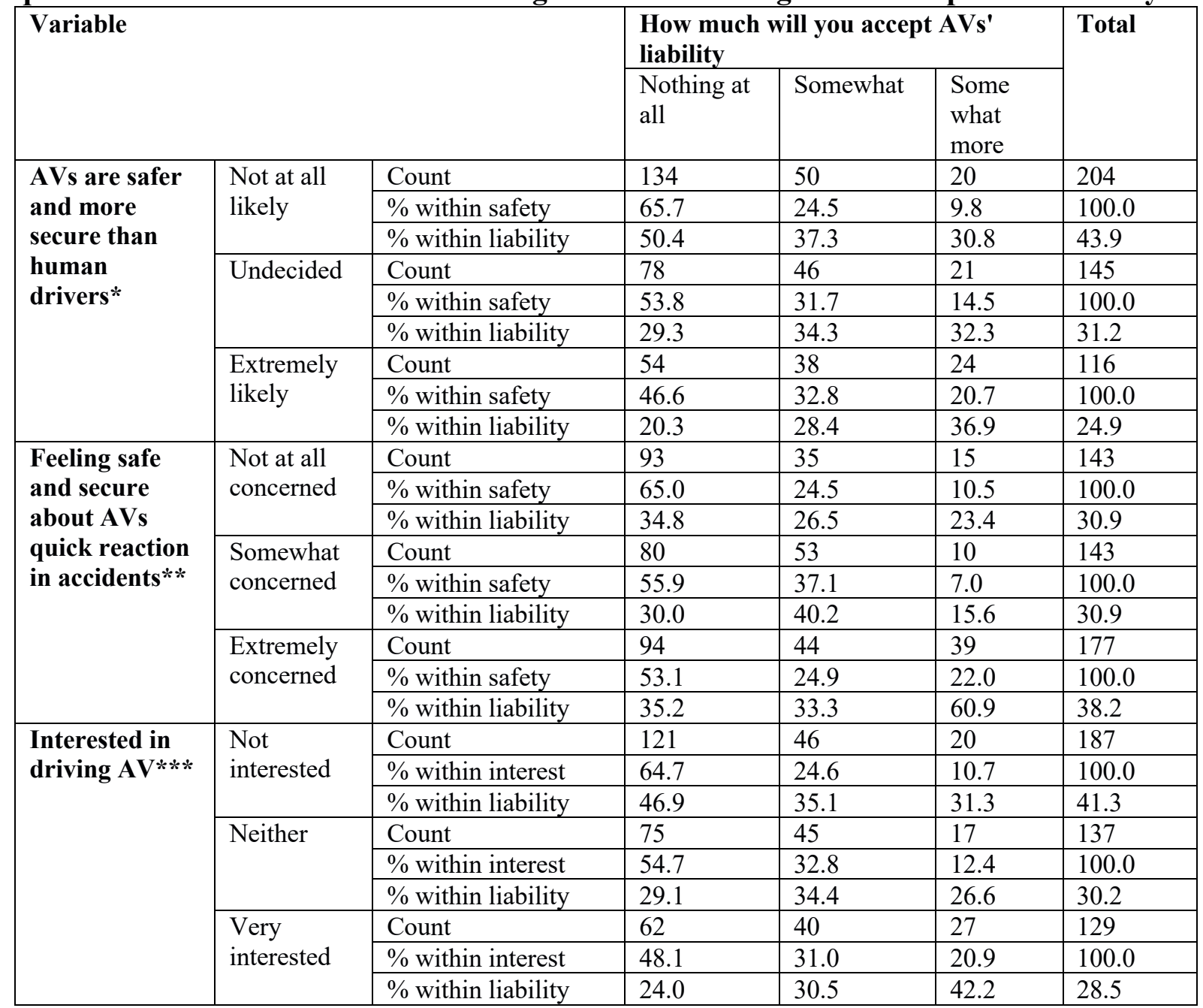

${ }^{*} \chi^{2}=13.83$, degrees of freedom $=4$, $\mathrm{p}$-value $=0.008$

$* * \chi^{2}=21.98$, degrees of freedom $=4, p$-value $=0.000$

$* * * \chi^{2}=12.08$, degrees of freedom $=4, \mathrm{p}-\mathrm{value}=0.017$

\subsection{Public's Decision about Purchasing AVs}

This sub-section presents the overall opinions regarding the purchase of AVs. Questions in this sub-section reveal whether people would wait to see the early adopters' opinion for buying AVs or not. Also, would people purchase AV once the technology is fully developed and tested and, if yes, what would be the most interesting aspects of the AVs which make participants buy them? The results from this sub-section would show how much AVs would be accepted by 
people which could also impact the market penetration of AVs. Table 10 represents the overall results of the evaluation in this regard.

According to Table 10, results revealed that people, in general, were not likely to purchase AVs once the technology is fully developed and tested, and it is available in the market. In this regard, around $69.3 \%$ of the people would 'extremely likely' tend to wait to see the early adopters' opinion about the application of AVs. Approximately $17.8 \%$ were neutral on this, where only $12.9 \%$ of the participants stated they would be so interested to adopt AVs so they would not wait to see the early adopters' opinions. Additionally, around $50 \%$ of the total participants stated they would 'not at all likely' tend to purchase AVs once the technology is fully developed and tested and they would wait to see the early adopters' opinions in this regard.

In addition to the assessments of this study, and as a general evaluation of the main reason for adopting AVs, people were asked what their main reason for purchasing an AV would be if they were interested in making a purchase. Answers to this question suggested that safe driving was the main benefit people saw in buying AVs, a benefit identified by $48.41 \%$ of those polled. Next in line among mentioned reasons for purchasing an AV was the reduction of emissions and fuel consumption and the automatic guidance and navigation systems of AVs. A group of participants submitted other answers as well, among which 'not interested in driving AVs' was the main response. The disabled respondents, however, did represent their interest in adopting AVs.

Table 10. The overall opinions regarding the purchase of AVs

\begin{tabular}{|l|l|l|}
\hline Variable & N & $\%$ \\
\hline Wait to see the early adopters' opinion for buying AVs & 61 & 12.9 \\
\hline Not at all likely & 84 & 17.8 \\
\hline Somewhat likely & 327 & 69.3 \\
\hline Extremely likely & 472 & 100.0 \\
\hline Total & 237 & 50.0 \\
\hline Purchasing AV once the technology is fully developed and tested & 25.1 \\
\hline Not at all likely & 119 & 24.9 \\
\hline Somewhat likely & 118 & 100.0 \\
\hline Extremely likely & 474 & \\
\hline Total & N & \\
\hline The most interesting aspects of the AVs which make participants buy them (MRA) & 48.4 \\
\hline Variable & 228 & 42.9 \\
\hline Safe driving & 181 & 38.4 \\
\hline Reduction of emissions and fuel consumption & 138 & 30.6 \\
\hline Automatic guidance and navigation systems & 144 & 29.3 \\
\hline Reduction of traffic congestion, queue, and delay & 5.7 \\
\hline Being fun and enjoying the free time when not driving & 202 & 27 \\
\hline Other & 27 \\
\hline
\end{tabular}

The study aimed to identify which factors had the greatest influence on users' willingness to purchase AVs. The result of such an evaluation could be useful for better understanding users' perceptions of and main reasons for adopting or rejecting AVs. Such results could be further used for market assessments. Hence, the study applied backwards linear regression method in this regard. Similary methods have been used in similar studies (Delclòs-Alió et al, 2019; Stefansdottir et al, 2019; Biejl et al, 2019). In this method, the study adds all independent variables into the model in the first step of analysis and correlates them with the dependent variable. Then, using the backward criterion, which is the probability of the $F$-test to remove an independent variable from the model $(F$-to-remove $<=0.100)$, the model removes the variable whose loss gives the most statistically insignificant deterioration of the model fit. For 
the case of the assessment in this study, the model deletes independent variables which do not correlate with the dependent variable of the model. Therefore, what will be left in the model would be merely the independent variables which substantially affect the model results. Then, the model repeats the process until no further variables can be deleted without a statistically significant loss of fit (Agresti, 2016; McCarthy et al., 2015). The dependent and independent variables of the model in this assessment are as follows:

Dependent Variable: Purchase AV when it is fully developed and tested Independent Variables (model predictors):

- Whether AVs would be safer and more secure than human drivers

- Feeling safe and secure about AVs' quick reaction in accidents

- Purchasing AV if the cost is not an issue

- Interest in driving AVs

- Having heard about AVs.

The model summary of the assessment (shown in Table 11) represents around $60 \% \mathrm{R}$-squared for each step of the model, meaning that the model's inputs can explain $60 \%$ of the observed variation. Also, the analysis of variance in the model (ANOVA test) shows $p$ values of 0.000 for all three steps, which are less than the 0.05 that verifies the model's goodness of fit.

Table 11. Model summary of the backward stepwise regression

\begin{tabular}{|c|c|c|c|c|c|c|}
\hline Model & $\mathbf{R}$ & R Square & \multicolumn{2}{|c|}{ Adjusted R Square } & \multicolumn{2}{|c|}{ Std. Error of the Estimate } \\
\hline 1 & .777 & 0.604 & \multicolumn{2}{|c|}{0.600} & \multicolumn{2}{|c|}{1.048} \\
\hline 2 & .776 & 0.603 & \multicolumn{2}{|c|}{0.599} & \multicolumn{2}{|l|}{1.049} \\
\hline 3 & .775 & 0.601 & \multicolumn{2}{|c|}{0.598} & \multicolumn{2}{|l|}{1.050} \\
\hline \multicolumn{7}{|c|}{ ANOVA } \\
\hline \multicolumn{2}{|l|}{ Model } & Sum of Squares & df & Mean Square & $\mathbf{F}$ & Sig. \\
\hline \multirow{3}{*}{1} & Regression & 716.995 & 5 & 143.399 & 130.506 & .000 \\
\hline & Residual & 469.185 & 427 & 1.099 & & \\
\hline & Total & 1186.18 & 432 & & & \\
\hline \multirow{3}{*}{2} & Regression & 715.168 & 4 & 178.792 & 162.465 & .000 \\
\hline & Residual & 471.012 & 428 & 1.100 & & \\
\hline & Total & 1186.18 & 432 & & & \\
\hline \multirow{3}{*}{3} & Regression & 712.815 & 3 & 237.605 & 215.336 & .000 \\
\hline & Residual & 473.365 & 429 & 1.103 & & \\
\hline & Total & 1186.18 & 432 & & & \\
\hline
\end{tabular}

Also, an investigation of the model coefficients would provide more insights into which independent variables might have more impact on users' willingness to buy AVs. The result of such an investigation is provided in Table 12. According to Table 12, all of the independent variables are added to the model in step one with a constant predictor, which the model acquires to run the process. Looking at the variable significance values, the independent variable 'Heard about AV' had the $p$ value of 0.198 , which is greater than 0.1 , which is the criterion for removal, meaning this variable causes the greatest degradation of the model fit in step one. Therefore, it is removed from the model, and the rest of the variables enter the next step for another round of correlation. In step two, 'Feeling safe and secure about AVs' quick reaction in accidents' has a $p$ value of 0.144 , which is greater than 0.1 and, for the same reason, it is removed from the model. Finally, the three independent variables left from step two enter the third step for another iteration of correlation. They are showing $p$ values of 0.000 , which are less than the removal criterion. This means that there is no other variable to make a statistically significant loss of fit to the model. Therefore, all three of them are considered valid and correlated to the dependent variable of the model. Out of the three remaining variables, the one with the greatest B- 
coefficients represents the variable with the greatest impact on the model significance. Therefore, 'purchase AV if the cost was not an issue', with a B-coefficient of 0.439 , is the variable that most substantially affects users' decisions about purchasing an AV. After that, 'interested in driving AV', and 'AVs are safer and more secure than human drivers' are the next most important ones, with B-coefficients of 0.285 and 0.143 , respectively.

Table 12. Model results of the backward stepwise regression

\begin{tabular}{|l|l|l|l|l|}
\hline Step & Variable & B & Std. Error & Sig. \\
\hline \multirow{5}{*}{} & (Constant) & -0.169 & 0.146 & 0.249 \\
\cline { 2 - 5 } & AVs are safer and more secure than human drivers & 0.132 & 0.041 & 0.001 \\
\cline { 2 - 5 } & $\begin{array}{l}\text { Feeling safe and secure about AVs quick reaction in } \\
\text { accidents }\end{array}$ & 0.043 & 0.031 & 0.172 \\
\cline { 2 - 5 } & Purchase AV if cost was not an issue & 0.433 & 0.041 & 0.000 \\
\cline { 2 - 5 } & Interested in driving AV & 0.280 & 0.043 & 0.000 \\
\cline { 2 - 5 } & Heard about AV & 0.043 & 0.034 & $\mathbf{0 . 1 9 8}$ \\
\hline 2 & Constant) & -0.111 & 0.140 & 0.426 \\
\cline { 2 - 5 } & AVs are safer and more secure than human drivers & 0.135 & 0.041 & 0.001 \\
\cline { 2 - 5 } & $\begin{array}{l}\text { Feeling safe and secure about AVs quick reaction in } \\
\text { accidents }\end{array}$ & 0.046 & 0.031 & $\mathbf{0 . 1 4 4}$ \\
\cline { 2 - 5 } & Purchase AV if cost was not an issue & 0.435 & 0.041 & 0.000 \\
\cline { 2 - 5 } & Interested in driving AV & 0.290 & 0.042 & 0.000 \\
\hline \multirow{3}{*}{3} & (Constant) & 0.013 & 0.111 & 0.907 \\
\cline { 2 - 5 } & AVs are safer and more secure than human drivers & 0.143 & 0.041 & $\mathbf{0 . 0 0 0}$ \\
\cline { 2 - 5 } & Purchase AV if cost was not an issue & 0.439 & 0.041 & $\mathbf{0 . 0 0 0}$ \\
\cline { 2 - 5 } & Interested in driving AV & 0.285 & 0.042 & $\mathbf{0 . 0 0 0}$ \\
\hline
\end{tabular}

\subsection{WTP for AVs}

This sub-section presents the results of survey questions asking about people's WTP for AVs. The results of this evaluation address whether AVs would be affordable for people or not, which impacts upon people's final decision regarding the adoption of AVs. The evaluation of users' WTP in this study is measured in three ranges of below $10 \%, 10 \%-20 \%$, and above $20 \%$ over the base price of the same vehicle in the traditional mode. In the results presented in Table 20, the respondents that said they were Not at all likely to purchase an AV once the technology had been tested (237) have been removed from this WTP analysis. It seemed logical to the researchers to remove this portion of the sample as they had indicated that they were not at all likely to purchase an AV and therefore the subsequent analysis is perhaps more meaningful. Given that almost half of the sample has been removed from the anlysis it was not possible to estimate a regression model or any more sophisticated statistical analysis. A cros-tabulation of WTP and age, gender and interest in driving an AV are presented in Table 13. These were the only variables presented as they were the only ones to provide statistically stable results.

Table 13. WTP for an AV

\begin{tabular}{|c|c|c|c|c|c|c|c|}
\hline & & \multicolumn{6}{|c|}{ WTP for AV in Addition to the Price of MDV } \\
\hline & & \multicolumn{2}{|c|}{ Below 10\% } & \multicolumn{2}{|c|}{$10 \%-20 \%$} & \multicolumn{2}{|c|}{ Above 20\% } \\
\hline & & $\mathrm{N}$ & $\%$ & $\mathrm{~N}$ & $\%$ & $\mathrm{~N}$ & $\%$ \\
\hline \multirow{3}{*}{$\begin{array}{l}\text { Gender } \\
(\mathrm{N}=236)^{*}\end{array}$} & Male & 26 & 38.8 & 53 & 53.0 & 35 & 50.7 \\
\hline & Female & 41 & 61.2 & 47 & 47.0 & 34 & 49.3 \\
\hline & Total & 67 & 100.0 & 100 & 100.0 & 69 & 100.0 \\
\hline \multirow{2}{*}{$\begin{array}{l}\text { Age } \\
(\mathrm{N}=236)^{* *}\end{array}$} & $18-35$ & 11 & 16.4 & 24 & 24.0 & 19 & 27.5 \\
\hline & $36-50$ & 25 & 37.3 & 42 & 42.0 & 42 & 60.9 \\
\hline
\end{tabular}




\begin{tabular}{|l|l|l|l|l|l|l|l|}
\hline & $50+$ & 31 & 46.3 & 34 & 34.0 & 8 & 11.6 \\
\cline { 2 - 8 } & Total & 67 & 100.0 & 101 & 101.0 & 69 & 100.0 \\
\hline \multirow{2}{*}{$\begin{array}{l}\text { Interest in } \\
\text { driving an AV } \\
(\mathrm{N}=226) * * *\end{array}$} & $\begin{array}{l}\text { Not } \\
\text { interested }\end{array}$ & 13 & 20.0 & 13 & 13.8 & 6 & 9.0 \\
\cline { 2 - 8 } & Neither & 19 & 29.2 & 39 & 41.5 & 26 & 38.8 \\
\cline { 2 - 8 } & $\begin{array}{l}\text { Very } \\
\text { interested }\end{array}$ & 33 & 50.8 & 42 & 44.7 & 35 & 52.2 \\
\cline { 2 - 8 } & Total & 65 & 100.0 & 94 & 100.0 & 67 & 100.0 \\
\hline
\end{tabular}

$* \chi^{2}=3.465$, degrees of freedom $=2, \mathrm{p}$-value $=0.177$

$* * \chi^{2}=24.392$, degrees of freedom $=6$, $p$-value $=0.000$

$* * * \chi^{2}=5.019$, degrees of freedom $=4, p$-value $=0.285$

\section{Discussion}

The results show that people, in general, were not very interested in driving AVs; only one-fifth of the population expressed a high interest while studies such as Bansal et al. (2017), Kyriakidis et al. (2015), Howard and Dai (2014), Casley et al. (2013), and KPMG (2012a) recorded above $70 \%$ of users' interest and acceptance of AVs. Also, the correlation between gender and interest shows that females, in general, were more neutral and less likely to be interested in driving AVs than males and this is in line with the result of the study by Bansal et al. (2017). Also, people in the age range of ' $26-35$ ' and ' $36-50$ ' looked more interested in driving AVs, whereas the age group '26-35' appeared to be the most interested age range of all. One reason for such high interest was that they believed AVs could be safer and more secure than cars driven by human drivers. The other age groups seemed to be less interested in driving AVs, as they did not feel safe and secure about AVs' abilities to react quickly in accident situations.

Only a small percentage of respondents believed that AVs would be much safer than cars with human drivers; people, in general, were mostly unsure or not likely to believe in AVs' safe and secure operation. However, above $60 \%$ of the people in previous studies such as Bansal et al. (2018), Howard and Dai (2014), Schoettle and Sivak (2014a, 2014b), and Casley et al. (2013) had a perception that AVs would be safer than human drivers. An important factor in the survey of this study, which influenced people's opinions about the matter was the number of cars they owned. Also, other results showed that feeling safe and secure about AVs' reaction in accidents affected people's perception of AVs' being safer and more secure than human drivers. The survey of this study showed that male drivers and those who had five cars or more believed more in AVs' extreme capabilities to increase safety and security, while people with only one car were less sure in this matter. In general, the male group had more trust that AVs were safer and more secure than human drivers. Also, Bansal et al. (2016) expressed that male drivers with higher income who had been in an accident before, have higher confidence in driving an AV. The assessment of people's interest in driverless AVs shows that people, in general, were not interested in AVs without steering wheels. The covariates of this assessment showed that concerns about AVs' safe and secure operation compared to human drivers, and concern about AVs' quick reaction in accidents reduced people's interest in driverless AVs. However, Laan and Sadabadi (2017) represent that AVs will have quicker reaction times than human drivers. Therefore, concerns about AVs' quick reaction might resolve if AVs can prove such capability. In general, interest in driving AVs and feeling safe and secure about AVs operation were statistically correlated. Those who were not interested in driverless AVs believed AVs would not be safer and more secure than human drivers, and they did not feel safe and secure about AVs' quick reaction in accidents.

Also, concerns about recording data had an extreme and negative impact on interest, since the majority of respondents did not accept AVs' recording of data because of concerns about the privacy of data. It should be noted that this study took place in an European Union country with 
high levels of data protection and therefore this finding may not be replicated in other jurisdictions. However, respondents who believed in the safe operation of driverless AVs were more likely to agree that AVs should record data, and so they were more likely to have an interest in purchasing AVs when the technology is fully developed than were the people who felt not at all safe and secure in driverless AVs. The correlation between the concern about the privacy of data and data recording is confirmed by the current study, as is the fact that privacy concerns have an impact on the agreement or disagreement with AV's recording data. Such concern about recording data could affect users' interest in and acceptance of AVs on public roads. The concerns about the recording data, type of stored data, availability of data and tracking individuals' locations were previously indicated by Rose (2017), Heaps (2016), and Fagnant and Kockelman (2015).

The evaluation of people's perceptions about driving with MDVs and AVs under the same driving conditions showed that people, in general, were slightly more concerned about driving with AVs than MDVs. However, since the focus of the current study was not on the evaluation of driving conditions, more investigation in this regard would be necessary to evaluate multiple driving scenarios.

The willingness to accept AVs' liability was assessed through three evaluations: interest in driving AVs, trust in AVs to be safer and more secure than human drivers and feeling safe and secure about AVs' quick reaction in accidents. In general, a review of all the analysis showed that $57.3 \%$ of people on average were not at all willing to accept liability for AVs. Even the majority of the people who had an interest in driving AVs, those who believed AVs would be safer and more secure than human drivers, and those who believed in AVs' quick reaction in accidents still had a very low willingness to accept the responsibility for the AV. Legal liability was also one of the main concerns in many public surveys such as Kyriakidis et al. (2015), Schoettle and Sivak (2014a, 2014b), Howard and Dai (2014) and KPMG (2012a). An average of $75 \%$ of the people in those studies were concerned about legal liability and that there is a need for completed regulatory frameworks in this matter.

The correlation between interest in driving AVs and in purchasing AVs shows that the extreme interest in driving AVs could affect decisions regarding purchasing AVs, with most of the respondents who were extremely interested in driving AVs having a tendency or - for the majority - an extreme tendency to purchase an AV. Also, the perception of users as to whether AVs are safer and more secure than human drivers could substantially impact users' decisions to purchase AVs. People who were not at all willing to purchase AVs believed AVs are not at all safer and more secure than human drivers. Such an opinion was also verified from the other side, in that those who did not believe in AVs' safe and secure operation were not willing to purchase AVs, which shows the correlation of the two variables. Furthermore, the study shows that extreme concern about AVs' quick reaction can reduce likeliness to purchase an AV.

Regarding the most important parameters that affect users' willingness to purchase AVs, a backward linear regression was conducted. The results showed that 'purchasing AV if the cost is not an issue' is the variable that most substantially affected users' decisions about purchasing an AV. Also, 65\% of the participants in the public survey conducted by Howard and Dai (2014) considered the cost to be a substantial concern regarding the adoption of an AV which verifies the results of this study in this regard. After cost, 'interest in driving AV', and 'AVs' safer and more secure operation comparing to human drivers' were the next two most essential parameters affecting the decision to purchase AVs. 
The survey of this study showed that interest in driving AVs and WTP for these vehicles are related, as those with a higher interest in driving AVs had a higher WTP and vice versa. Also, results indicated that nearly $43 \%$ of the participants had below USD 5,900 WTP in addition to the base price of the same vehicle in the traditional mode. Therefore, the average payable price for those $43 \%$ for one of the vehicles in evaluated in this study (Table 21) is around USD 65,377 which is far below the estimated price of an AV (USD 150,000) in 2012 (Howard and Dai, 2014; KPMG, 2012b; Priddle and Woodyard, 2012). Also, the public survey by Liu et al. (2019) revealed that around $26 \%$ of the participants would be unwilling to pay extra for AVs and approximately $40 \%$ would be willing to spend more than USD 2,900. Additionally, the reviewed studies show that the average WTP to add full self-driving automation is around USD 5,500 which is far below the estimated price of an AV which is also in line with the results of the current study.

\section{Conclusions}

\subsection{Weaknesses}

The main limitations of the research presented are as follows:

- There was a very low willingness to participate in the pilot survey since many of those who were contacted to participate in the survey knew that their responses were not going to be used for statistical assessments or to get published at all.

- The initial assessment of the surveys revealed that some of the demographic groups had a smaller number of participants than the rest. However, those small groups were not merged or so they can be comparable with the Census (CSO, 2018) groups. Such an issue might be considered as a weakness of the survey. However, before running the analysis, all demographic groups were checked for model fitting, standard deviation, and errors to make sure that such an issue does not make a substantial (negative) impact on the survey results.

\subsection{Policy and Industry Recommendations}

The following industry and policy making recommendations can be made based on the research:

- Legal liabilities of the vehicles in case of accidents; addressing how much the legal liability should be divided between the participants in accidents related to AVs

- An authorised agency for accessing the recorded travel data, if the record of data by AV might be necessary

- Which government body or agency should take responsibility if the big project of adopting AVs fails and what would be the best course of action in such a case

- Designing new methods for the safe and secure record of the vehicle data, if it is going to be recorded, in a form of local data servers which cannot be penetrated by hackers

\subsection{Future Research Directions}

On concluding the research presented in this paper the following are seen as the main areas for future research in this field:

- The research presented demonstrates that individuals had concerns on where the data that is collected from AV use is housed and who can access this data. Further research is needed in this area to determine who should have access to this data and how can trust issues could vary in different jurisdictions.

- Further research on how WTP may vary depending upon personal circumstances such as VMT and urban and rural dwellers is needed.

\subsection{Main findings}


On concluding the research presented in this paper the following are seen as the main areas for future research in this field:

- In general, only a small number of respondents felt AVs would be safer than MDVs

- The sample indicated that AVs without steering wheels did not appeal to potential users

- Our sample did indicate that recording of personal data while using an AV was of concern and they had concerns over personal privacy

- Over half of the sample indicated they were not willing to accept personal liability when driving an AV

- WTP for an AV increased, as one would expect, with interest in driving an AV

\section{References}

Araz, T., Hazel Si Min, L., Governing autonomous vehicles: emerging responses for safety, liability, privacy, cybersecurity, and industry risk, Transport Reviews, Vol 39, 2019, pp 103-128

Aggelos, S., Martin, B., Francesco, C. Impacts of automated vehicles on travel behaviour and land use: an international review of modelling studies. Transport Reviews. 2019, Vol. 39 Issue 1, p29-49.

Bansal, P., Kockelman, K.M., \& Singh, A. (2016). Assessing public opinions of and interest in new vehicle technologies: An Austin perspective. Transportation Research Part C: Emerging Technologies, 67, 1-14.

Becker, F., Axhausen, K, W. Literature review on surveys investigating the acceptance of automated vehicles. Transportation, 2017, Vol 44, pp 1293-1306

Beirigo, B.A., Schulte, F., \& Negenborn, R.R. (2018). Integrating People and Freight Transportation Using Shared Autonomous Vehicles with Compartments. IFACPapersOnLine, 51(9), 392-397.

Biehl, A., Ermagun, A., Stathopoulos, A. Utilizing multi-stage behaviour change theory to model the process of bike share adoption, Transport Policy, 2019, Vol 77, pp 30-45

Bosch, P.M., Becker, F., Becker, H., \& Kay, W.A. (2018). Cost-based Analysis of Autonomous Mobility Services. Journal of Transport Policy, 64, 76-91.

Casley, S.V., Jardim, A.S., \& Quartulli, A.M. (2013). A Study of Public Acceptance of Autonomous Cars. BSc Thesis. Computer Science Department, Worcester Polytechnic Institute.

Chan, C.H. (2017). Advancements, Prospects, and Impacts of Automated Driving Systems. International Journal of Transportation Science and Technology. 6(3), 208-216.

CSO. (2017). Central Statistics Office of Ireand.

Delclòs-Alió, X., Marquet, O., Miralles-Guasch, C. Keeping track of time: A Smartphonebased analysis of travel time perception in a suburban environment. Travel Behaviour and Society, 2017, Vol 9, pp 1-9

El-Habil, A. An Application on Multinomial Logistic Regression Model. Pakistan Journal of Statistics and Operation Research. 2012 8(2), 271-291

Fagnant, D.J., \& Kockelman, K. (2015). Preparing a Nation for Autonomous Vehicles: Opportunities, Barriers and Policy Recommendations. Transportation Research Part A: Policy and Practice, 77, 167-181. 
Gkartzonikas, C., Gkritza, K. What have we learned? A review of stated preference and choice studies on autonomous vehicles. Transportation Research Part C: Emerging Technologies, Vol 98, 2019, pp 323-337

Heaps, R. (2016). Data Collection for Self-Driving Cars Could Be Risking Your Privacy. Autotrader. Retrieved from https://www.autotrader.com/car-shopping/data-collectionself-driving-cars-could-be-risking-257144.

Howard, D., \& Dai, D. (2014). Public Perceptions of Self-Driving Cars: The Case of Berkeley, California. Transportation Research Board, 93rd Annual Meeting.

Hulse, L., Xie, H., \& Galea, E. (2018). Perceptions of Autonomous Vehicles: Relationships with Road Users, Risk, Gender and Age. Journal of Safety Science, 102, 1-13.

IrishTimes. (2019). Top 100 Cars for 2019. The Irish Times. Retrieved from https://www.irishtimes.com/life-and-style/motors/top-100

Katrakazas, C., Quddus, M., Chen, W. H, \& Deka, L. (2015). Real-Time Motion Planning Methods for Autonomous On-Road Driving: State-Of-The-Art And Future Research Directions. Transportation Research Part C: Emerging Technologies, 60, 416-442.

Kaur, K., \& Rampersad, G. (2018). Trust in Driverless Cars: Investigating Key Factors Influencing the Adoption of Driverless Cars. Journal of Engineering and Technology Management, 48, 87-96.

KPMG. (2012b). Self-Driving Cars: The Next Revolution. Klynveld Peat Marwick Goerdeler $(K P M G) \&$ Center for Automotive Research (CAR), Connected Vehicle Technology $(C V T)$. Retrieved from http://cargroup.org/?module=Publications\&event=View\&pubID $=87$.

Kyriakidis, M., Happee, R., \& De-Winter, J.C.F. (2015). Public Opinion on Automated Driving: Results of an International Questionnaire among 5000 Respondents. Transportation Research Part F: Traffic Psychology and Behaviour, 32, 127-140.

Laan, Z.V., \& Sadabadi, K.F. (2017). Operational Performance of a Congested Corridor With Lanes Dedicated to Autonomous Vehicle Traffic. International Journal of Transportation Science and Technology, 6, 42-52.

Laerd. (2019). Multinomial Logistic Regression Using SPSS Statistics. Laerd Statistics. Last Checked: March 2019. Retrieved from: https://statistics.laerd.com/spsstutorials/multinomial-logistic-regression-using-spss-statistics.php.

Liu, P., Guo, Q., Ren, F., Wang, L., \& Xu, Z. (2019). Willingness to Pay for Self-Driving Vehicles: Influences of Demographic and Psychological Factors. Transportation Research Part C: Emerging Technologies. 100, 306-317.

Marçal, R., Fabio, A., Bruna Habib, C., Arthur Miranda, N., Danilo Alves de, L., Joel Yutaka, S., Isabelle, N., Andre Luiz, Z. Autonomous vehicles: scientometric and bibliometric review. Transport Reviews. Jan2019, Vol. 39 Issue 1, p9-28. 20p

Neiger, C. (2016). How Much Do Driverless Cars Cost? The Motley Fool. Retrieved from http://www.fool.com/investing/2016/08/04/how-much-do-driverless-cars-cost.aspx

Noy, I., Shinar, D., \& Horrey, W. (2018). Automated Driving: Safety Blind Spots. Journal of Safety Science, 2, 68-78.

Nikitas, A., Njoya, E. T., \& Dani, S. (2019). Examining the myths of connected and autonomous vehicles: analysing the pathway to a driverless mobility paradigm. International Journal of Automotive Technology and Management, 19(1-2), 10-30.

OECD. (2017). International Transport Forum (ITF) Outlook 2017. Organisation for Economic Co-Operation and Development. Retrieved from http://dx.doi.org/ $\underline{10.1787 / 9789282108000-e n .}$ 
Papadoulis, A., Quddus, M., \& Imprialou, M. (2019). Evaluating the Safety Impact of Connected and Autonomous Vehicles on Motorways. Accident Analysis and Prevention, $124,12-22$.

Payre, W., Cestac, J., \& Delhomme, P. (2014). Intention to Use a Fully Automated Car Attitude and a Priori Acceptability. Transportation Research Part F: Traffic Psychology

Priddle, A., \& Woodyard, C. (2012). Google discloses costs of its driverless car tests. USA Today. Retrieved from

http://content.usatoday.com/communities/driveon/post/2012/06/google-discloses-costsof-its-driverless-car-tests/1\#.WB0i7oXXJfo.

Rakotonirainy, A., Schroeter, R., \& Soro, A. (2014). Three Social Car Visions to Improve Driver Behaviour. Pervasive and Mobile Computing, 14, 147-160.

Rezaei, A (2020) Examining the efficiency of autonomous vehicles in highway transport. PhD Thesis, Trinity College Dublin. Available online:

http://www.tara.tcd.ie/handle/2262/92496

Rose, N. (2017). The Privacy Implications of Autonomous Vehicles. Data Protection Report. Retrieved from https://www.dataprotectionreport.com/2017/07/the-privacy-implicationsof-autonomous-vehicles/.

Schoettle, B., \& Sivak, M. (2014b). A survey of Public Opinion about Autonomous and SelfDriving Vehicles in the U.S., the U.K., and Australia. University of Michigan, Ann Arbor, Transportation Research Institute, UMTRI-2014-21.

Schoettle, B., \& Sivak, M. (2014c). Public Opinion about Self-Driving Vehicles in China, India, Japan, the U.S., the U.K., and Australia, Michigan, USA. University of Michigan, Ann Arbor, Transportation Research Institute, UMTRI-2014-30.

Stefansdottir, H., Næss, P., Ihlebæk, C. Built environment, non-motorized travel and overall physical activity. Travel Behaviour and Society, 2019, Vol 16, pp 201-213

Smith, B.W. (2013). Managing Autonomous Transportation Demand. Santa Clara Law Review, 52, 1401.

Underwood, S. (2014). Automated Vehicles Forecast: Expert Forecast and Roadmap for Sustainable Transportation - Automated, Connected, and Electric Vehicle Systems. Vehicle Symposium Opinion Survey. Institute for Advanced Vehicle Systems, University of Michigan - Dearborn. Retrieved from http://graham.umich.edu/media/files/LC-IAACE-Roadmap-Expert-Forecast-Underwood.pdf.

Xu, Z., Zhang, K., Min, H., Wang, Z., Zhao, X., Liu, P. What drives people to accept automated vehicles? Findings from a field experiment. Transportation Research Part C: Emerging Technologies, Vol 95, 2018, pp 320-334 